\title{
Merging Health and Social Services
}

Merging health and social care, including prevention, to improve quality of life and well-being is a form of population health that is especially effective for the older population. In 1993, the seminal article by McGinnis and Foege shined light on the fact that the United States needs to integrate more social supports and prevention into the healthcare system. ${ }^{1}$ The article claimed that 95 percent of the healthcare spending in the United States goes to medical care, while only 5 percent is dedicated to population health measures. McGinnis and Foege make the case that the imbalance of health to social care expenditure is the reason for the poor health outcomes realized in the United States. The authors attributed 40 percent of deaths to behaviors, 30 percent to genetics, 15 percent to social determinants, and 5 percent to environmental exposures. This left ten percent of health outcomes attributable to medical care. In the following years, the quote has been repeated over and over, and the percentage of health outcomes attributable to healthcare has been adapted over time. The highest percentage quoted is 30. Most experts use the quote that is considered generous: healthcare is only responsible for 20 percent of health outcomes. 
Health is a state of complete physical, mental, and social wellbeing and not merely the absence of disease or infirmity. ${ }^{2}$ (World Health Organization)

Today people are living with increasing health and social needs over a longer period of time. In response, best practices in aging shift the main goal of care from curing illness to improving the quality of life and well-being in the extra years people live. This goal is often referred to as shortening the gap between life expectancy and healthy life expectancy. ${ }^{3}$

Public and private health systems that serve older adults are steadily moving toward comprehensive approaches that integrate healthcare with social supports and prevention. This approach includes non-clinical, individualized interventions that support the biological, psychological, social, and environmental needs and honor the priorities of the patient. The approach also maintains a focus on the social determinants of health of the patient.

The fact that medical care historically has had limited impact on the health of populations has been known for many years. ${ }^{4}$

The interviews summarized below detail interventions that address the social determinants of health including the condition, accessibility, and safety of the home, community connection and inclusion, ${ }^{5}$ and access to healthcare, transportation, and food. The interviewees also describe preventative programs for chronic disease self-management, medication management and review, improving function, increasing independence, and mitigating the risk of falling.

\section{The Home Environment}

Staying at home is cost-effective and keeps people connected to their community supports and activities. The home environment can also present risk factors that need to be mitigated to preserve function, independence, health, safety, and quality of life. 


\section{Access to Care}

Access to care is an ongoing problem for older adults who have challenges leaving and returning home. These challenges are often due to the lack of adequate transportation and the need for home modifications such as wider doorways, more supportive railings, and elevators, or ramps. Bringing care and support to the home and community can improve access for this cohort.

\section{Access to Transportation}

Lack of transportation is a barrier to successful aging in place. In 2015, an estimated 54 percent, totaling 3.9 million older adults, faced challenges accessing transportation. ${ }^{6}$ In the same year, an estimated 15.5 million older adults lived in communities with poor or no public transportation. ${ }^{7}$ Older adults without access to transportation are more likely to remain isolated at home, miss visits to the doctor, and not make necessary errands including shopping for groceries, resulting in further physical and mental health decline.

\section{Access to Food}

Food insecurity as defined by the US Department of Agriculture is a lack of consistent access to enough food for an active healthy life. ${ }^{8}$ In 2015, over eight percent of older adults in the United States experienced food insecurity. ${ }^{9}$ That percent is projected to double by $2025 .{ }^{10}$ Food insecurity has negative health and well-being implications. Older adults who are food insecure experience similar levels of inability to perform the activities of daily living ${ }^{11}$ as seniors who are 14 years older but are food secure. ${ }^{12}$ Food insecure seniors are more likely to be depressed and in poor or fair health. ${ }^{13}$

Malnutrition ${ }^{14}$ can be caused by many factors including the inability to afford groceries or to leave the house and travel to a grocery store, 
medications that cause stomach upset, and dental problems including ill-fitting dentures and tooth decay. Malnutrition in older adults leads to falls, ${ }^{15}$ physical and cognitive decline, and mortality. ${ }^{16}$ Sixty percent of seniors who present at the emergency department arrive at risk for malnutrition or already malnourished. ${ }^{17}$

\section{Chronic Disease Self-Management}

Approximately 80 percent of seniors have at least one chronic disease and 68 percent have two or more. ${ }^{18}$ Chronic disease self-management empowers older adults with knowledge and planning to keep their chronic illnesses in check and to manage the associated conditions. Validated programs have shown to improve quality of life and lower health system usage and $\operatorname{cost}^{19}$ by significantly reducing emergency department visits and hospitalizations. ${ }^{20}$ On average, the number of chronic illnesses that people live with increases with age. ${ }^{21}$ As the number of chronic illnesses a person has increases, so does the likeliness of poor functional status ${ }^{22}$ resulting in declining ability to perform the activities of daily living. ${ }^{23}$

\section{Medication Management}

Almost one half of all prescriptions in the United States are for older adults. ${ }^{24}$ The more medications one takes, the higher the risk of adverse drug reactions. ${ }^{25,26,27}$ Older adults are at a higher risk for adverse drug reactions. ${ }^{28}$ Ten to 30 percent of hospital admissions of older adults are attributed to adverse drug reactions. ${ }^{29}$ That number rises to 33 percent for people older than $75 .{ }^{30}$ Adverse drug reactions result in high healthcare usage and costs and cause substantial morbidity and mortality. ${ }^{31}$ An estimated 40-50 percent of seniors who are aging in place and receiving home- or community-based care are not taking their medications properly. ${ }^{32}$ Approximately one half of adverse drug reactions in older adults are preventable. ${ }^{33}$ 


\section{Function and Independence}

Independence, aging in place, and quality of life are heavily dependent on the ability to perform the activities of daily living (ADLs). Having the ability to perform the ADLs is the number one factor of quality of life for those living with dementia. ${ }^{34}$ Limitations in performing ADLs are predictors for early nursing home admission, frailty, and mortality. ${ }^{35}$

Older adult falls are increasing and, sadly, often herald the end of independence. Healthcare providers can make fall prevention a routine part of care in their practice, and older adults can take steps to protect themselves. ${ }^{36}$ (Tom Frieden, MD, MPH, former Director of the CDC)

\section{Falls}

The World Health Organization considers falls to be a major global public health crisis. ${ }^{37}$ Falls are the leading cause of death and injury for older adults. ${ }^{38}$ Globally, the over $37,000,000$ falls that are severe enough to require medical attention are responsible for more than 17,000,000 disability adjusted life years ${ }^{39}$ lost. ${ }^{40}$ Falls can also result in costly nursing home admissions. ${ }^{41}$ In the United States, one in four people age 65 and older fall annually, sending an older adult to the emergency department every 11 seconds. ${ }^{42}$ After a fall, a person is twice as likely to fall again..$^{43}$ The average cost of hospitalization for a fall of an older adult is over US\$30,000.00 and 800,000 older adults are hospitalized annually as a result of a fall. ${ }^{44}$ The annual medical costs of falls of older adults in the United States are estimated at US $\$ 31$ billion. ${ }^{45}$ The benefit for home modification interventions to prevent falls for older adults has shown to be at least 12 times the cost of the intervention. ${ }^{46}$ That benefit increases by 60 percent for those who have already experienced a fall. ${ }^{47}$

The American health system does not invest in social services and prevention the way it should. Partners in Care is trying to impact that allocation. (June Simmons) 


\section{June Simmons, Partners in Care Foundation ${ }^{48}$}

June Simmons is the founder of the Partners in Care Foundation and a cofounder of the national Evidence Based Leadership Council. ${ }^{49}$ Partners in Care collaborates with providers to pilot interventions for prevention and chronic disease self-management. After the proof-of-concept phase of the interventions, Partners in Care encourages health system uptake, with the goal of making the evidence-based programs standard protocol.

Any payer is happy with cost savings and better health outcomes.

\section{Readmissions}

In her interview, June noted that more than 15 percent $^{50}$ of patients insured through Medicare are readmitted to the hospital within one month of discharge, costing Medicare US\$26 billion annually ${ }^{51}$ US\$17 billion of that is deemed preventable. The Partners in Care Transitions Choices ${ }^{52}$ program is designed to prevent readmissions by engaging home and community care networks to provide follow-up care and social supports such as transportation and food. Additionally, they conduct risk assessments to prevent medication conflicts and falls. The care team also provides chronic disease self-management coaching.

\section{Nursing Home Avoidance}

Nursing homes have become the default post-discharge route because Medicare reimburses for up to 100 days of nursing home stay after hospital discharge. Without safe, coordinated, multidisciplinary care available in the home, many patients have no option other than nursing homes (skilled nursing facilities) for recuperative care upon hospital discharge. Because nursing homes also offer permanent "custodial" care, it can be easy to become "stuck" there and never make it back home. Nursing homes are not the best option for many post-hospital patients, 
and they also have high rates of readmission. The Partners in Care transitions program enables hospitals to discharge patients directly to their homes. ${ }^{53}$ The program results in improved customer satisfaction and cost savings. The net savings to Medicare from 30,000 people who participated in the care transitions program are estimated at US\$21 million.

One of the biggest issues in healthcare is the lack of coordination. This lack of coordination greatly affects medications management.

\section{Medication Review}

The goal of the Partners in Care medication review programs is to reduce adverse drug reactions. June mentioned that, according to the Centers for Disease Control, those 65 and older are at twice the risk of going to the emergency department due to adverse drug reactions, compared with all those under age 65. Older adults are also 7 times more likely to be admitted to the hospital from the emergency department than other cohorts. June also noted that nearly 177,000 seniors experience emergency department visits and 100,000 are admitted to the hospital each year due to adverse drug reactions. The HomeMeds and HomeMedsPlus medication safety programs target older, frail people living with multiple chronic conditions who have recently been discharged from the hospital or nursing home. This cohort takes many medications and is at a high risk of complications. They are also often under the care of multiple specialists who might not be coordinating the medications they are prescribing. Hospitalizations generally result in the doctor prescribing more medications that have potential conflict with others the patient has at home. The prescriptions might be duplications with a different name, color, or shape than medications the patient is already taking and will continue to take after discharge.

Partners in Care designed software to support their medication review. The medication library is updated regularly because medications change often. The evidence-based algorithms detect certain medication conflicts, potential adverse effects like risk for gastrointestinal bleeding, falls, dizziness or confusion, and duplications. Any potential medication-related 
problems are reviewed by a pharmacist who then makes recommendations for any needed changes to the patient's primary care physician. Partners in Care provides online training and periodic reviews with organizations that implement HomeMeds as part of their care plan. To date, the HomeMeds and HomeMedsPlus programs are operational at 73 sites in 20 states.

Certain classes of drugs, such as psychotropics, cardiovascular medications, and non-steroidal anti-inflammatory drugs, are especially dangerous and problematic when used improperly.

During her interview, June shared some stories from the medication review field. One older gentleman who started falling when he returned home from the hospital was dedicated to taking all his medications. Unfortunately, he was taking them all at once at breakfast so he would not forget any. The falls were occurring because he was taking multiple doses of blood pressure medication at the same time and one of his medications was a sleeping pill. Another patient wanted to be sure to follow the instructions to take her medications with food. The directions on the medications were to take them three times per day. Because the patient only ate one meal per day at lunchtime, she was taking all of her medications at one time.

The HomeMeds program is a medication safety review. The HomeMedsPlus program includes psychosocial, functional, fall-risk, and environmental assessments with the medication review. A care manager uses the information gleaned from the assessments and review to design individualized care and service plans. The assessments are a form of upstream prevention that address the social determinants of health such as a hole in the roof or lack of food, transportation, or temperature control.

Although the assessments and the services delivered can be relatively simple, they have profound impact (Fig. 9.1). A recent pilot program resulted in a 22 percent lower rate of hospital readmissions and a nearly 13 percent lower rate of emergency department visits. The estimated cost savings from hospital avoidance was 53 percent. In addition, 77 percent of the patients needed equipment or home modifications to improve their 


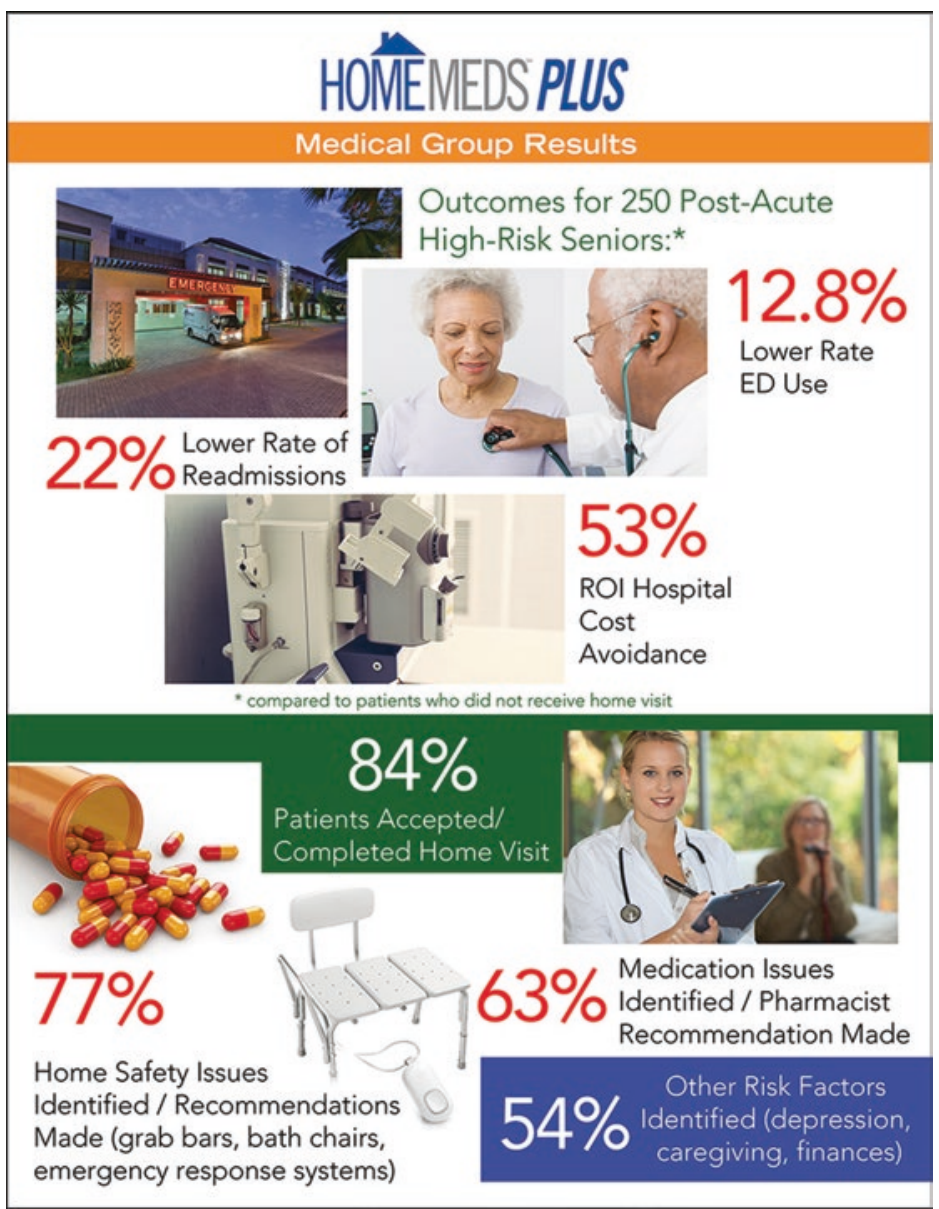

Fig. 9.1 Results of HomeMeds PLUS Pilot Program. Source: Partners in Care Foundation

ability to live safely at home. The medication reviews revealed medication problems for 63 percent of the patients visited. Fifty-four percent of the patients visited had psychosocial risk factors including depression, issues with caregiving, and financial concerns. June noted that the outcomes might seem surprising because the patients visited were receiving highquality medical care, but this highlights the importance of addressing 
non-medical issues to avoid hospital readmissions. June also mentioned that she was encouraged by the fact that 84 percent of the patients who were offered HomeMedsPlus accepted and completed the program.

Partners in Care uses clinicians who are already visiting the home to conduct the assessments and medication reviews. This saves on time and transportation costs. Non-clinicians can also conduct the review. June suggested that possibly volunteers or meal delivery people could be enlisted to conduct the reviews to keep the costs low and improve access.

Many are working to escalate the needed changes in population health management to make the disruptive home and community-based interventions readily available.

\section{Chronic Disease Self-Management and Education}

Kaiser Permanente and Stanford University collaborated to design chronic disease self-management education programs. Insurers offer the program to their patients to improve health outcomes. Partners in Care provides the programs within a seven miles radius of clusters of patients because they found that transportation was a barrier to patient participation. The programs are also available online along with a self-study toolkit. Because the evidence-based programs have resulted in cost reduction through improved chronic disease management, governmental entities are interested in expanding them throughout the United States.

Why would you address falls without conducting a medication review? Why address chronic disease without diabetes, or diabetes without hypertension? These programs are meant to work together.

\section{Prevention}

Partners in Care collaborated with leaders around the United States to create the Evidence Based Leadership Council that collaboratively designs and disseminates evidence-based preventative programs for balance and 
falls, fitness, exercise, and chronic disease self-management. The programs include: A Matter of Balance, ${ }^{54}$ Healthy IDEAS, ${ }^{55}$ PEARLS, ${ }^{56}$ Healthy Moves, ${ }^{57}$ EnhanceWellness, ${ }^{58}$ EnhanceFitness, ${ }^{59}$ and Fit and Strong. ${ }^{60}$ Community organizations offer the programs at the local level across the country.

Another program that blends healthcare delivery with social support is CAPABLE (Community Aging in Place-Advancing Better Living for Elders).

As a nurse making house calls in Baltimore, I have seen patients who had to crawl to the front door to let me in. Others had to throw me the keys from the upper window because they could not come down to the first floor to open the door. ${ }^{61}$ (Sarah Szanton)

\section{Sarah Szanton, CAPABLE ${ }^{62}$}

Sarah Szanton is the Director of policy for the Center on Innovative Care in Aging ${ }^{63}$ and Professor at the Johns Hopkins School of Nursing. She studies health disparities in older adults and works to eliminate health and quality-of-life differences for seniors across socioeconomic and racial lines.

House calls are not the same as treating someone in an office setting. I came face to face with what mattered to people when I was in their home. I saw a clear picture of the environment they were living in. I found holes in floors and shaky bannisters.

The CAPABLE program engages a home repair professional, an occupational therapist, and a nurse over a four-month period to support the functional goals and medical priorities of older people who wish to remain living at home. CAPABLE participants are mostly low-income, African American people age 65 and older and have limitations with one or more $\mathrm{ADL}$ and two or more independent activities of daily living (IADLs). ${ }^{64}$ The aim of the program is to improve physical function as measured by the ability to perform the ADLs and IADLs. This type of program is referred to a restorative care in many countries because the focus is on functional improvement. Goal-oriented programs empower 
patients to direct their own care and support through varied, and often competing, health and social needs. The success of goal-oriented care is measured, in part, by the ability to meet the goals of the patient.

My patient was the same person. She had lived the same one hundred and one years. She had the same physiology and biology, yet she needed less medication because of the physical environment.

\section{Honoring the Goals of the Participant}

The CAPABLE team members meet individually with the program participant and the occupational therapist designs a work order based on the participant's goals. In her interview Sarah noted that the success of the program is dependent upon the team honoring the goals of the participant over what the team members think the goals should be. Sarah believes that the program is successful because participants are engaged and determined when they are challenged to meet their own goals. Participant goals might include being able to go downstairs or upstairs in their home, prepare meals, or take a shower. To support the goal of someone who wants to go up and down the stairs, the home repair team member will likely install a second bannister, make the existing bannister more secure, and add brighter lighting to the staircase. The occupational therapist might work on arm and leg strength. For the participant who wishes to prepare meals, the home repairs professional might widen the doorway for wheelchair access to the kitchen, adjust counter tops, and install a refrigerator and stove that are accessible to someone in a wheelchair. For the participant wishing to shower, the occupational therapist might work on balance and strength while the home repair team member would install grab bars in the shower and around bathroom. For most concerns the nurse would conduct a medication review to ensure that functional issues are not a result of medication duplication or error.

We created a new role for nurses. Nurses have traditionally not been focused on function to the degree that CAPABLE does. 


\section{Outcomes}

\section{Functional Improvement}

Sarah mentioned that she was initially surprised with the outcomes of a recent randomized control trial because no other program has realized nearly the success in functional improvement as CAPABLE. During the Centers for Medicare \& Medicaid Innovation project, CAPABLE reduced participant disability by one half. Seventy-five percent of the participants improved their ability to perform the ADLs. The average ADL limitation reduction went from 4 to 2 . The CAPABLE team labeled improvements as unsuccessful even if a participant went from no ability to perform an $\mathrm{ADL}$ to having only minor limitations performing the same ADL by the end of the program. Sarah noted that this indicates that the results, as positive as they are, are conservative. The IADL improvements realized were also impressive. Sixty-five percent of the participants improved their ability to perform their IADLs. Sarah put these results into further perspective by explaining that this patient population, when not participating in CAPABLE, is likely to experience further functional loss during the four-month period.

Another important outcome of improved function is that improved ability to perform the ADLs and IADLs prevents falls. This is why CAPABLE was recently named a leading falls prevention program by the National Council on Aging.

\section{Quality of Life and Mental Health}

Participants who are able to live in their homes safely and have the functional ability to remain independent experience improved quality of life and less depression. On average, the CAPABLE program participants experienced reduced levels of depression from moderate to mild. This improvement in mental health is not minor. The difference between moderate and mild depression could mean the difference in the need for anti-depressant medication. The improved quality of life of the participants does not end with them. Their well-being affects their families and 
their communities. Sarah mentioned that many of the CAPABLE participants were foster parents. She also acknowledged the benefit of keeping civically minded, caring older adults functional enough to provide stable parenting for local foster children. It is a win-win for the older adult and the community. Being a foster parent also fulfills the need for purpose and generativity felt by older adults. ${ }^{65}$

\section{Hospitalizations and Nursing Home Placements}

CAPABLE participants experienced much lower rates of hospitalization than the control group. They also entered nursing homes at a rate three percent lower than the control group, reducing their likelihood of nursing home placement by 50 percent.

\section{Cost}

The CAPABLE program generates health system cost savings that are six times the cost of implementation. Because of this saving, providers who receive value-based insurance reimbursements are eager to adopt the program.

\section{Looking Forward}

As health systems around the world reorganize to meet the needs of the growing older population, it is our hope at ACCESS Health International that all systems of care for older adults will be designed to treat the whole person including the biopsychosocial and environmental factors of health. We also envision increasing efforts upstream with improved preventative interventions and a firm eye on the social determinants that drive health system usage, inequity, and suffering. The literature and the two interviews above provide evidence to support that such a design will improve access to care and support, reduce health system costs, and contribute to well-being. 
Social inclusion is crucial to the well-being of older adults. Creating inclusive spaces and communities fills many psychological and social needs of older adults and has shown to improve physical health. Such spaces and communities are a powerful antidote to the pervasive systemic ageist stereotypes and prejudices seen around the world. In our next chapter, we write about inspiring programs that connect older adults to their communities and enable a life of purpose, inclusion, learning, and intergenerational connections.

The full interviews referenced in this chapter can be found at this link: www.accessh.org/agingwell.

\section{Notes}

1. McGinnis, J.M. \& Foege, W.H. (1993). Actual causes of death in the United States. Journal of the American Medical Association, 240(18), 2207-2212.

2. http://www.who.int/about/mission/en/. Accessed October 2017.

3. Healthy life expectancy is defined as the period of life without physical barriers to normal life functioning.

4. McGinnis, J.M., Williams-Russo, P., \& Knickman, J.R. (2002). The case for more active policy attention to health promotion. Health Affairs, 21(2), 78-93.

5. Please refer to Chap. 8 for more about loneliness interventions and social inclusion.

6. AARP. Waiting for a ride: Transit access and America's aging population. Accessed October 2017.

7. Transportation for America (2011). http://t4america.org/maps-tools/ seniorsmobilitycrisis2011/. Accessed October 2017.

8. https://www.ers.usda.gov/topics/food-nutrition-assistance/food-security-in-the-us/. Accessed October 2017.

9. National Council on Aging. https://www.ncoa.org/news/resources-forreporters/get-the-facts/senior-hunger-facts/. Accessed October 2017.

10. Feeding America. (2017). Senior hunger fact sheet. www.feedingamerica.org/hunger-in-america/senior-hunger-facts.html. Accessed October 2017. 
11. Activities of daily living include personal care such as bathing, dressing, grooming, feeding oneself, and toileting.

12. Gundersen, C. \& Zillak, J.P., (2015). Food insecurity and health outcomes. Health Affairs, Health Affairs, 34(11), 1830-1839.

13. Ibid.

14. Malnutrition is defined by the WHO as deficiencies, excesses, or imbalances in a person's intake of energy and/or nutrients resulting in low height and or weight and insufficiencies of micronutrients such as vitamins and minerals. Malnutrition can also cause overweight or obesity, resulting in diseases such as stroke, heart disease, cancer, and diabetes.

15. Vivanti, A.P., McDonald, C.K., Palmer, M.A., \& Sinnott, M. (2009). Malnutrition associated with increased risk of frail mechanical falls among older people presenting to an emergency department. Emergency Medicine Australasia, 21(5), 386-394.

16. Pereira, G.F., Bulik, C.M., Weaver, M.A., Holland, W.C., \& PlattsMills, T.F. (2015). Malnutrition among cognitively intact, noncritically ill older adults in the emergency department. Annals of Emergency Medicine, 65(1), 85-91.

17. Ibid.

18. National Council on Aging. Chronic disease self-management programs. www.ncoa.org/healthy-aging/chronic-disease-self-management-programs/. Accessed October 2017.

19. Ibid.

20. Ahn, S.N., Basu, R., Smith M.L., Jiang, L., Lorig, K., Whitelaw, N., \& Ory, M.G. (2013). The impact of chronic disease self-management programs: Healthcare savings through a community based intervention. BioMed Central, 13, 1141.

21. US Department of Health and Human Services. (2014). Multiple chronic conditions-A strategic framework: Optimum health and quality of life for individuals with multiple chronic conditions. https:/www. hhs.gov/sites/default/files/ash/initiatives/mcc/mcc_framework.pdf. Accessed June 2017.

22. Salive, M.E. (2013). Multimorbidity in older adults. Epidemiologic Reviews, 35(1), 75-83.

23. Ralph, N.L., Mielenz, T.J., Parton, H., Flatley, A.M. \& Thorpe, L.E. (2009). Multiple chronic conditions and limitations in activities of daily living in a community based sample of older adults in New York City in 2009. Preventing Chronic Disease, 10, E199. 
24. Tangiisuran, B., Gozzoli, M.P., Davies, J.G. \& Rajkumar C. (2010). Adverse drug reactions in older people. Rev Clin Gerontol, 23(3), 246-259.

25. Brahma, K.K., Wahlang, J.B., Marak, M.D. \& Sangma, M.Ch. (2013). Adverse drug reactions in the elderly. J Pharmacol Pharmacother, 4(2), 91-94.

26. Centers for Disease Control. https://www.fda.gov/ForConsumers/ ConsumerUpdates/ucm399834.htm. Accessed October 2017.

27. Tangiisuran, B., Scutt, G., Stevenson, J., Wright, J., Onder, G., Petrovic, M., van der Cammen, T.J., Rajkumar, C., \& Davies, G. (2014). Development and validation of a risk model for predicting adverse drug reactions in older people during hospital stay: Brighton Adverse Drug Reactions Risk (BADR) Model. PLoS One, 9(10), e111254.

28. An adverse drug event occurs when a person experiences harm because of a medication.

29. Nair, N.P., Chalmers, L., Peterson, G.M., Bereznicki, B.J., Castelino, R.L. \& Bereznicki, L.R. (2016). Hospitalization in older patients due to adverse drug reactions-The need for a prediction tool. Clin Interv Aging, 11, 497-505.

30. Pretorius, R.W., Gataric, G., Swedlund, S.K. \& Miller, J.R. (2013). Reducing the risk of adverse drug events in older adults. Am Fam Physician, 87(5), 331-336.

31. Thomas, R., Huntley. A.L., Mann, M., Huws, D., Elwyn, G., Paranjothy, S. \& Purdy, S. (2014). Age Aging, 43(2), 174-187.

32. Partners in Care Foundation. https://www.picf.org/innovations2/. Accessed October 2017.

33. Pretorius, R.W., Gataric, G., Swedlund, S.K. \& Miller, J.R. (2013). Reducing the risk of adverse drug events in older adults. Am Fam Physician, 87(5), 331-336.

34. Andersen, C.K., Wittrup-Jensen, K.U., Lolk, A., Andersen, K., \& Kragh-Sørensen, P. (2004). Ability to perform activities of daily living is the main factor affecting quality of life in patients with dementia. Health and Quality of Life Outcomes, 2, 52.

35. CDC. https://www.cdc.gov/pcd/issues/2013/13_0159.htm. Accesses October, 2017.

36. CDC. https://www.cdc.gov/media/releases/2016/p0922-older-adultfalls.html. Accessed October 2017. 
37. WHO. http://www.who.int/mediacentre/factsheets/fs344/en/. Accessed October 2017.

38. Ibid.

39. Disability adjusted life year is the years of healthy life lost due to poor health or disability.

40. Ibid.

41. Isenring, E., Baker, J., \& Kerr, G. (2013). Malnutrition and falls risk in community-dwelling older adults. J Nutr Health Aging, 17(3), 277-279.

42. National Council on Aging. https://www.ncoa.org/news/resources-forreporters/get-the-facts/falls-prevention-facts/. Accessed October 2017.

43. Centers for Disease Control and Prevention. https://www.cdc.gov/ homeandrecreationalsafety/falls/adultfalls.html. Accessed October 2017.

44. Ibid.

45. Ibid.

46. Keall, M.D., Pierse, N., Howden-Chapman, P., Guria, J., Cunningham, C.W., \& Baker, M.G. (2017). Cost-benefit analysis of fall injuries prevented by a programme of home modifications: A cluster randomized control trial. Inj Prev, 23(1), 22-26.

47. Ibid.

48. https://www.picf.org. Accessed October 2017.

49. http://www.eblcprograms.org. Accessed October 2017.

50. On the Medicare Hospital Compare Website, it says: National rate of all cause hospital-wide readmission $=\mathbf{1 5 . 3} \% \mathrm{https}: / \mathrm{www} \cdot$ medicare. gov/hospitalcompare/profile.html\#vwgrph=1\&profTab $=4 \& \mathrm{ID}=05008$ $2 \&$ Dist $n=1.3 \&$ dist $=50 \& 1$ oc $=93030 \& 1$ a $t=34.2054029 \&$ $\operatorname{lng}=-119.1681373$

According to AHRQ, in 2014 the number was 17.3\%. https://www. hcup-us.ahrq.gov/reports/statbriefs/sb230-7-Day-Versus-30-Day-Readmissions.pdf

More info:

In 2003, almost 20 percent of Medicare patients who were discharged from a hospital were readmitted within 30 days. The readmission rates declined from 21.5 percent in 2007 to 17.8 percent in 2015 for targeted conditions (i.e., a set of specific diagnoses measured by Medicare), and from 15.3 to 13.1 percent for non-targeted conditions [36]. 
51. Center for Health Information and Analysis. (2015). Performance of the Massachusetts health care system series: Focus on provider quality. http:// www.chiamass.gov/assets/Uploads/A-Focus-on-Provider-Quality-Jan-2015. pdf. Accessed October 2017.

52. Not actually a name; our actual readmission reduction programs are called "Care Transition Choices" and HomeMedsPlus.

53. We have no documentation that we enable hospitals to discharge earlier. I've never heard anyone representing a hospital say that, have you?

54. https://www.ncoa.org/resources/program-summary-a-matter-of-balance/. Accessed October 2017.

55. https://www.ncoa.org/resources/program-summary-healthy-ideas/. Accessed October 2017.

56. https://www.cdc.gov/learnmorefeelbetter/programs/depression.htm. Accessed October 2017.

57. https://www.ncoa.org/resources/program-summary-healthy-moves-foraging-well/. Accessed October 2017.

58. http://www.projectenhance.org/enhancewellness.aspx. Accessed October 2017.

59. http://www.projectenhance.org/enhancefitness.aspx. Accessed October 2017.

60. https://www.fitandstrong.org. Accessed October 2017.

61. http://nursing.jhu.edu/faculty_research/research/projects/capable/capable-news.html.

62. https://nursing.jhu.edu/faculty_research/research/projects/capable/ index.html.

63. https://nursing.jhu.edu/excellence/aging/center/index.html. Accessed October 2017.

64. Instrumental activities of daily living include preparing meals, house cleaning, managing finances, shopping, using the phone or possibly the computer, medication adherence, and pet care.

65. Generativity is the sharing of wisdom and knowledge to guide the next generations. Psychologist Erik Erikson coined the phrase. 
Open Access This chapter is licensed under the terms of the Creative Commons Attribution 4.0 International License (http://creativecommons.org/licenses/ by/4.0/), which permits use, sharing, adaptation, distribution and reproduction in any medium or format, as long as you give appropriate credit to the original author(s) and the source, provide a link to the Creative Commons licence and indicate if changes were made.

The images or other third party material in this chapter are included in the chapter's Creative Commons licence, unless indicated otherwise in a credit line to the material. If material is not included in the chapter's Creative Commons licence and your intended use is not permitted by statutory regulation or exceeds the permitted use, you will need to obtain permission directly from the copyright holder.

(c) 